\title{
CAN EXERCISE REPLACE AIRWAY CLEARANCE TECHNIQUES IN CYSTIC FIBROSIS? A SURVEY OF
}

PATIENTS AND HEALTHCARE PROFESSIONALS.

AUTHORS N.J. Rowbotham ${ }^{* 1}$, S.J. Smith ${ }^{1}$, G. Davies ${ }^{2}$, T. Daniels ${ }^{3}$, Z.C. Elliott ${ }^{4}$, K. Gathercole ${ }^{5,6}$, O.C. Rayner ${ }^{7}$, A.R. Smyth ${ }^{1}$

*Corresponding author

Dr Nicola J Rowbotham,

Address: Evidence Based Child Health Group, Division of Child Health, Obstetrics \& Gynaecology, E Floor East Block, Queens Medical Centre, Nottingham NG7 2UH.

Email: nicola.rowbotham@nottingham.ac.uk

Telephone: (+44) 01158230079

\section{AFFILIATIONS}

1University of Nottingham, Evidence Based Child Health Group, Nottingham, United Kingdom, 2UCL Great Ormond Street Institute of Child Health, London, United Kingdom, 3 York Hull Adult Cystic Fibrosis Centre, York Teaching Hospital NHS Foundation Trust, York, United Kingdom, ${ }^{4}$ Parent of Children with CF, Nottingham, United Kingdom, 5 University of Leeds, Leeds, United Kingdom, 6 Person with CF, Leeds, United Kingdom, 7 Person with CF, Plymouth, United Kingdom,

Word count: 1308 , abstract 150

\section{Abbreviations:}

ACT: Airway Clearance Technique

HCP: Healthcare Professionals

JLA: James Lind Alliance

NIHR: National Institute for Health Research

pwCF: people with CF

PSP: Priority Setting Partnership 


\section{ABSTRACT}

Airway clearance techniques (ACTs) are recommended in cystic fibrosis (CF) to prevent accumulation of secretions and lung infection. "Can exercise replace chest physiotherapy for people with CF?" is one of the CF community's top 10 research questions. We conducted an online survey of the CF community to gather data on current ACT use, recommendations, reported adherence levels and exercise strategies used. There were 488 respondents: 194 (40\%) people with CF (pwCF), 141 (29\%) family and 153 (31\%) healthcare professionals (HCPs) (mostly physiotherapists). Only 10/285 (4\%) of pwCF do no exercise at present and 163/303 (54\%) already incorporate exercise into ACTs. ACTs were omitted by $128 / 267$ (48\%) of pwCF when they exercised. Nearly all $(110 / 129,93 \%)$ of HCPs currently recommend exercise to support ACTs. A trial replacing some or all ACTs with exercise, was supported by $80 / 110(73 \%)$ of HCPs, with an additional $9 / 110(8 \%)$ willing to consider in selected patients.

\section{KEYWORDS}

Exercise. Airway clearance techniques. Cystic fibrosis. Clinical trial. Co-production. Priority setting. 


\section{INTRODUCTION}

Cystic fibrosis (CF) is characterised by a failure of mucociliary clearance and accumulation of viscid secretions in the airway, leading to recurrent infection. To mitigate this process, CF treatment guidelines recommend the regular use of an airway clearance technique (ACT), with exercise as an adjunct(1). In people with CF (pwCF), exercise such as running or cycling, increases ease of sputum expectoration, minute ventilation and respiratory flow(2). A comparison of one ACT with treadmill exercise showed that these approaches performed similarly over a single session(3). These studies suggest that exercise might be a replacement rather than an adjunct to some or all of a patient's ACT programme.

In a recent patient engagement exercise, the James Lind Alliance (JLA) Priority Setting Partnership (PSP) in CF, the patient and clinical community jointly identified the top 10 questions for clinical research in CF(4). "Can exercise replace chest physiotherapy for people with CF?" was one of these research priorities. Exercise also featured as a topic of importance in the US CF Foundation's Insight CF project(5). We conducted an online survey in order to understand further how the CF community currently uses exercise to supplement or replace ACT, and to assess the acceptability to patients and healthcare professionals (HCPs) of a clinical trial to investigate replacing ACT with exercise.

\section{METHODS}

This work was led by a steering group representative of the CF community (lay and professional) and supported by the UK National Institute for Health Research (NIHR) under the title "James Lind CF2". An online questionnaire was co-produced using SurveyMonkey ${ }^{\mathrm{TM}}$ to help us understand which ACTs are currently undertaken by people with CF and recommended by HCPs, current levels of reported adherence and exercise strategies used (See online supplement 1). The survey was designed to be inclusive, with no minimum age or restrictions on location, and was open over 5 weeks in December 2018-January 2019. There were separate streams for lay and professional respondents to complete. It was promoted via our Twitter ${ }^{\mathrm{TM}}$ account (@questionCF), professional networks, UK CF Trust, US CF Foundation Community Voice group and the NIHR. The survey data were downloaded to Excel for quantitative analysis (closed questions) and NVivo for thematic analysis (free text comments) in order to generate topics which represented recurring themes.

\section{RESULTS}

There were 488 respondents, with 335 (69\%) from the lay community. Of these 194 (58\%) were people with CF and 141 (42\%) family of people with CF. Of the HCPs, 63\% were physiotherapists. The greatest number of respondents were from the UK $(n=220,45 \%)$ followed by North America $(n=134,28 \%$ ). Median age of respondents with CF was 33 years (range 14-74 years) and median age of those whose parents or family answered on their behalf was 8 years (range $1-33$ years). Survey respondent characteristics are summarised in appendix table 1 . Not all respondents answered every question so denominators will vary (supplement 2 ).

Figure 1a shows the type of exercise most popularly undertaken by people with CF and grading of intensity using metabolic equivalent of tasks (METs)(6), with walking (moderate intensity) and running (high intensity) the most popular. The majority of people with CF exercise 3-5 times a week with only 10/285 (4\%) of lay respondents reporting no exercise (figure 1b). Almost all (110/129, 93\%) HCPs currently recommend exercise as a way of supporting ACTs and recommend all intensities of exercise (figure 1c). A full list of the top 20 exercises with METs are in appendix table 2. 
Figure 1. Current exercise habits and intensity in CF. a) The top five types of exercise currently undertaken by people with CF as indicated by the survey respondents $(n=266)$. Coded from free text answers where respondents could give more than one exercise type. Corresponding exercise intensity with metabolic equivalence values (METs) (6) shown for each type of exercise. Cut offs for exercise intensity (in METs) were as follows: light $=<3$, moderate $=3-5.9$, high $=>6(6)$. b) Frequency of exercise undertaken at present by survey respondents $(n=285)$. Single response allowed per respondent. c) Intensity of exercise believed to be beneficial by HCPs $(n=110)$. Multiple responses allowed per respondent.

a.

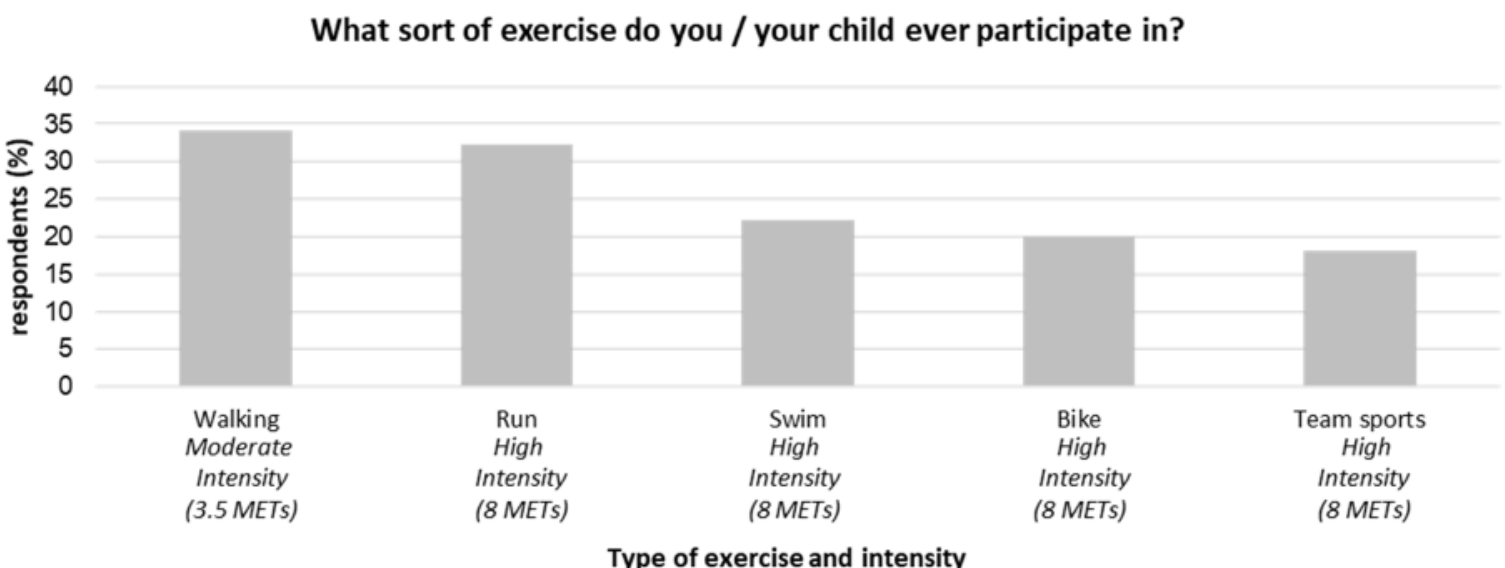

b.

Do you/your child do any regular exercise as part of your normal routine?



c.

\section{In terms of airway clearance, which forms of exercise do you feel would benefit people with CF?}

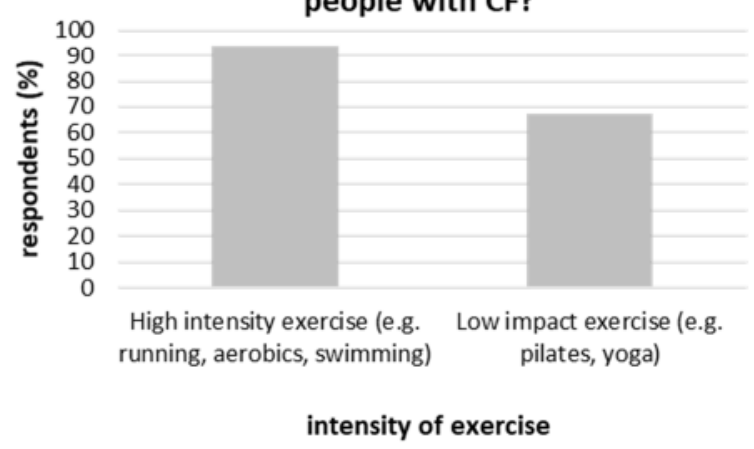

People with CF do exercise for many reasons (figure 2a), with the most popular being for lung health $(204 / 279,73 \%)$ followed by general health $(185 / 279,66 \%)$ and enjoyment $(168 / 279,60 \%)$. Only two of 277 respondents felt that exercise does not help clear their lungs. Better sputum production $(184 / 275,67 \%)$, better lung function $(175 / 275,64 \%)$ and "feeling better" $(173 / 275,63 \%)$ were the top three ways that people with CF believe exercise is working to clear their lungs (figure $2 \mathrm{~b}$ ). Poor health $(161 / 266,61 \%)$, time $(38 / 266,14 \%)$ and weather $(15 / 266,6 \%)$ were the top three factors that stopped people with CF from exercising. Six percent $(15 / 266)$ replied that nothing ever gets in the way of exercise (figure 2c).

Only $35 \%$ of respondents with CF (98/284) reported using an App or tracker to monitor physical activity and 68 reported the type of device used. Wearable devices were used by $85 \%$ of those who told us what they used (58/68) and Apps by $15 \%(10 / 68)$. Of the wearable devices, Fitbit ${ }^{\mathrm{TM}}$ was the most popular (figure $2 \mathrm{~d}$ ). 
Figure 2. Drivers behind exercise. a) Reasons why people with CF exercise ( $n=279)$. Multiple responses allowed per respondent. b) Effects of exercise $(n=275)$. Multiple responses allowed per respondent c) Factors that stop people with CF from exercising $(n=266)$. ). Coded from free text answers where respondents could give more than one reason. d) Current app/technology use to aid exercise in people with CF ( $n=284$ ). Single response allowed per respondent.

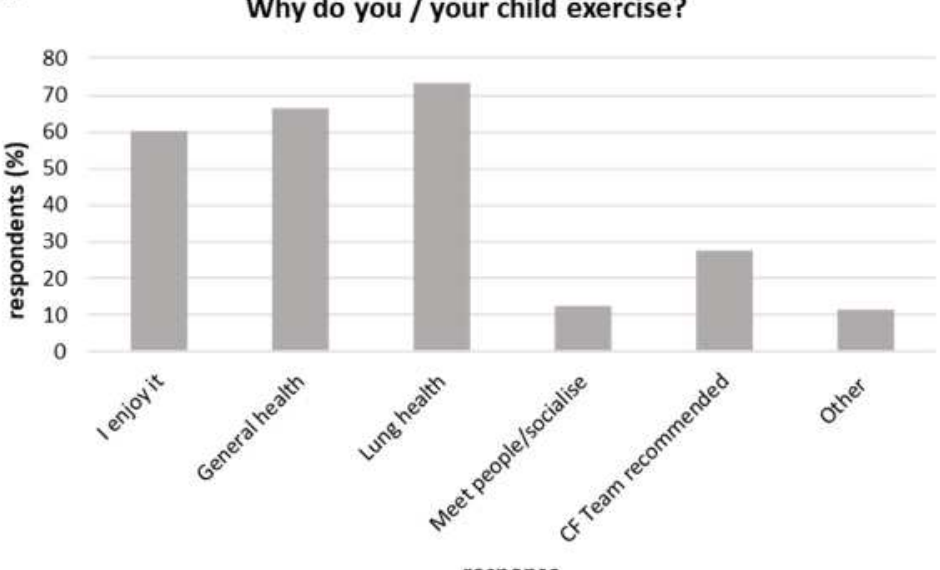

C.



How would you tell if exercise was working to clear your / your child's lungs?
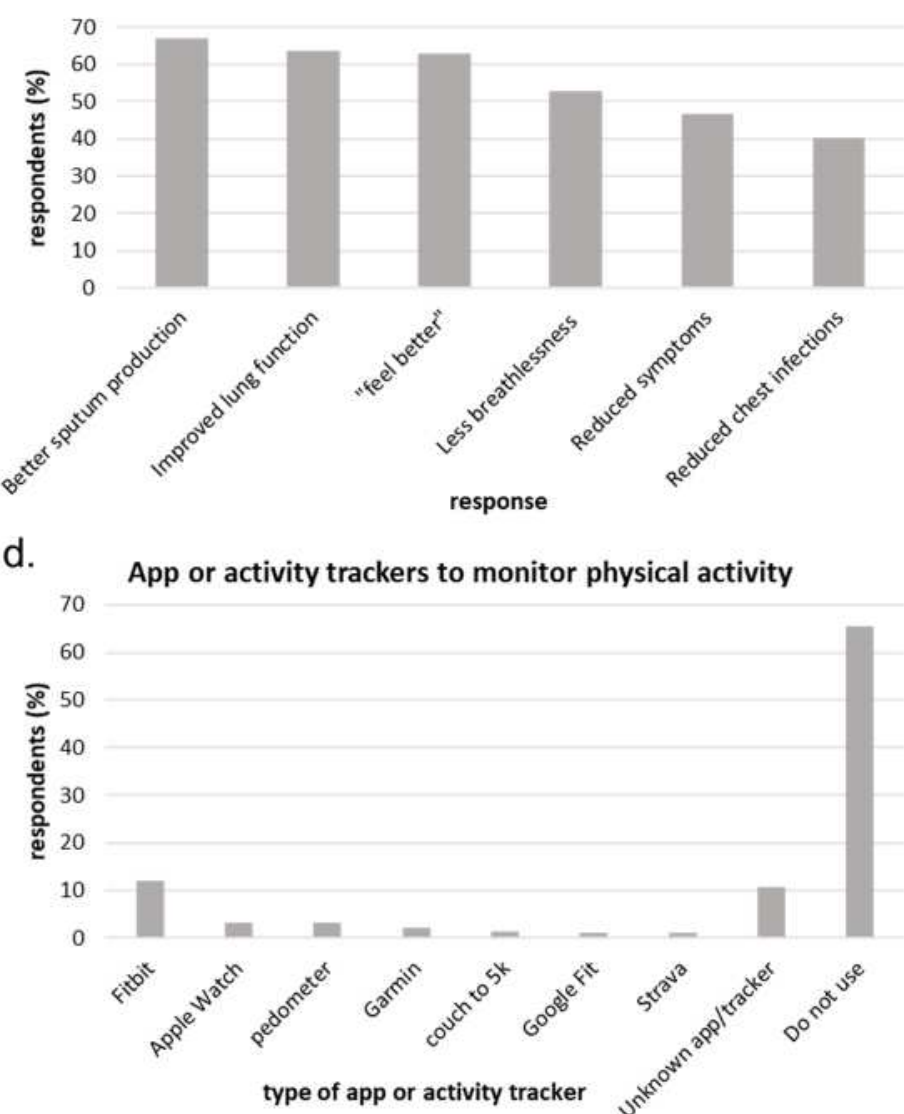
Time spent on ACTs varied among respondents, with, on average, people with CF spending $30 \mathrm{mins}$ one hour a day over two sessions (figure $3 a$ and $3 b$ ) (range 0-3 hours a day over 0-5 sessions a day). Over half of people with CF $(163 / 303,54 \%)$ already incorporate exercise into their ACTs and almost a quarter $(73 / 303,24 \%)$ already do exercise alone for their ACT (figure 3c). Almost 60\% (180/302) of respondents admit to skipping their ACTs, with "life", "how I feel" and "time" being the main explanatory themes given for this.

Almost half $(128 / 267,48 \%)$ of all respondents may drop their prescribed ACT if they have exercised (figure 3d) (including 49\% (80/163) of those who incorporate exercise into their ACT). Nearly three quarters $(80 / 110,73 \%)$ of HCPs would support a trial of replacing some or all airway clearance techniques with exercise, with an additional $8 \%(9 / 110)$ willing to consider supporting a trial in selected patients (figure $3 \mathrm{~d}$ ). Online supplement 3 shows trial suggestions collected from the CF community. 
Figure 3. Current ACT practice and views on future trials. a) Average number of sessions spent daily on ACT ( $n=302)$. Single response allowed per respondent. b) Average time spent daily on ACT $(n=301)$. Single response allowed per respondent. c) The use of exercise, ACT and combinations of the two in survey respondents $(n=303)$. Multiple responses allowed per respondent $d$ ) Numbers reporting dropping an ACT session when they have exercised $(n=267)$. Single response allowed per respondent. e) Support for a trial of replacing ACT with exercise $(n=110)$. Single response allowed per respondent.

a. How many times a day do you/ your child do ACT?



C.

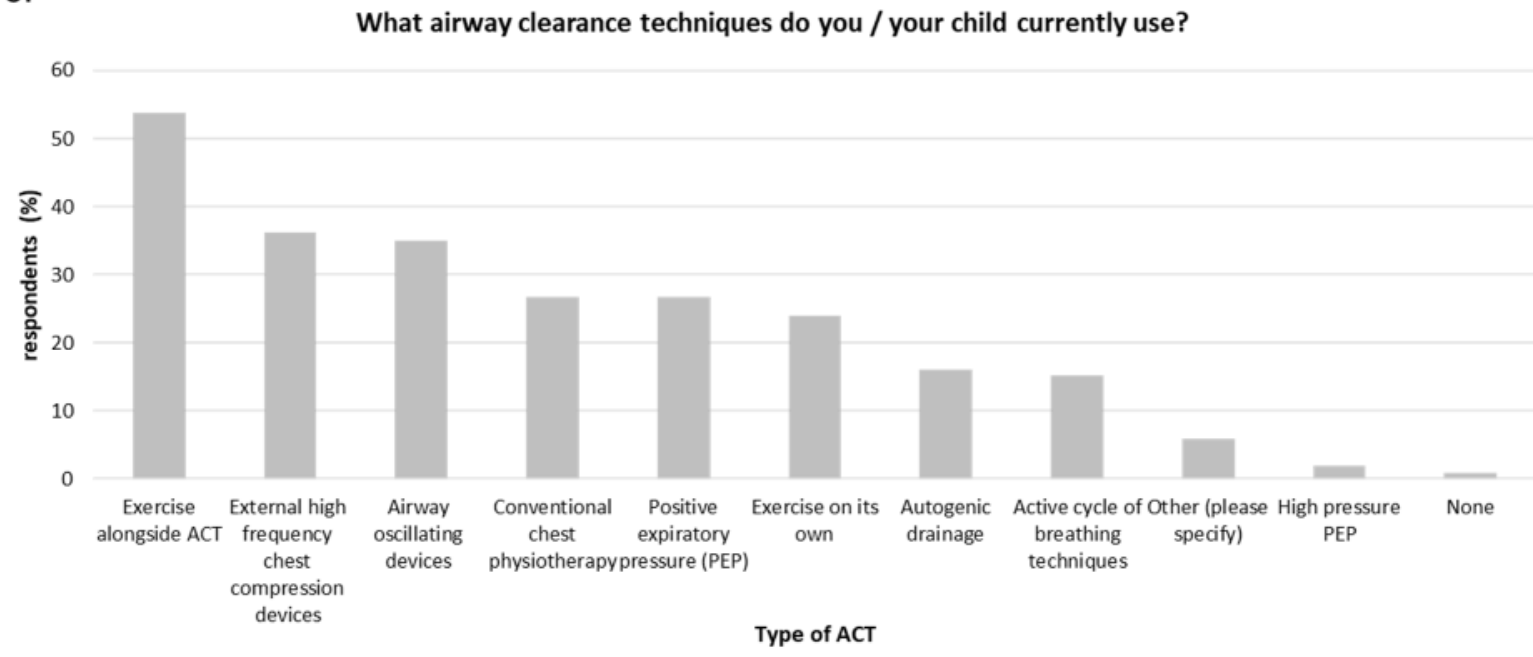

d.

Do you / your child ever drop an airway clearance session if you have exercised?



b. How long do you / your child spend each day doing airway clearance?



time spent e.



\section{DISCUSSION}

Here we have explored current exercise use in people with CF and the influence it has on their ACT regimens. Most people with CF already incorporate exercise into their lives. Activity levels are higher than the general population. Around $20 \%$ of the UK population are classed as "inactive"(7) 
whereas only $4 \%$ of our CF population claimed to do no exercise. Almost half of people with CF regularly omit their prescribed ACT if they have exercised. This level of adherence is consistent with previous studies that have estimated adherence levels with CF physiotherapy to be $40-50 \%(8,9)$.

We found that most HCPs would support a trial replacing ACT with exercise. A recent Cochrane review looking at exercise for $\mathrm{CF}$ found 15 studies assessing the effect of exercise on people with $\mathrm{CF}$ but all included control groups who were not exercising rather than omitting any ACT (10). A systematic review comparing current clinical trials with the JLA top 10 did find two trials that loosely matched with "Can exercise replace physiotherapy?"(11). One is a feasibility study evaluating whether those who adhere to an exercise programme can then drop their ACT(12). The other is a crossover study looking at the effect of mucus clearance from exercise, ACT or sitting still(13). These studies aim to enrol small numbers (17 and 25 patients respectively) and results are, as yet, unpublished. A larger, adequately powered, multicentre trial is needed.

As with all anonymous online surveys, there are limitations. What people self-report and what they actually do can be quite different. However, an advantage of anonymity is that it allows respondents to be more honest without worry of repercussions. People with CF may be more conscious of things they can do to improve their health or it may be that the subsection of the CF population taking part in our survey are more interested in exercise, leading to response bias.

Many people with CF omit ACT if they have exercised. There is support amongst professionals for a trial of replacing current ACT with exercise. The data presented here will allow us to design clinical studies which will begin to answer the question of whether exercise can replace some ACT. Although most of our respondents were from the UK and US over a quarter were from elsewhere in the world. It is therefore reasonable to conclude that the themes and trends noted are applicable to the global CF population.

\section{Acknowledgements}

We would like to thank all the people with CF and their families, and the multi-disciplinary CF health care professionals for taking part in this survey. Members of the James Lind Alliance CF2 steering group include: Brownlee K, Collins S, Daniels T, Davies G, Duff AJA, Elliot ZC, Gathercole K, Hurley MN, Leighton PA, Rayner OC, Rowbotham NJ, Smith SJ, Chandran S, Nash EF, Smyth AR (Chair), Wilson P. 


\section{Declarations}

\section{Conflict of Interests Statement}

NJR has given lectures at meetings sponsored by TEVA. AS has provided consultancy for Vertex and holds a current unrestricted research grant from Vertex. He has taken part in clinical trials sponsored by Vertex, Raptor and Insmed. He has given lectures at meetings sponsored by Teva and Vertex. GD has given lectures at meetings sponsored by Chiesi.

\section{Funding}

This work was supported by the UK CF Trust. NJR is an NIHR Academic Clinical Fellow at University of Nottingham. GD is an NIHR Clinical Trials Fellow and was previously supported by a NIHR Clinical Lectureship at UCL.

\section{Authors' contributions}

All authors were involved in the study design process and contributed in preparation of the manuscript. 
Appendix Table 1. Survey participant characteristics

\begin{tabular}{|c|c|c|}
\hline Characteristic & $\mathbf{n}$ & $\%$ \\
\hline Total survey participants & 488 & - \\
\hline \multicolumn{3}{|l|}{ Category of Respondent } \\
\hline Lay persons & 335 & $69 \%$ \\
\hline Person with CF & 194 & $(58 \%)$ \\
\hline $\begin{array}{l}\text { A parent of a child or } \\
\text { children with CF }\end{array}$ & 130 & $(39 \%)$ \\
\hline $\begin{array}{l}\text { Spouse or partner of a } \\
\text { person with } \mathrm{CF}\end{array}$ & 2 & $(1 \%)$ \\
\hline $\begin{array}{l}\text { Other relative or friend } \\
\text { of a person with CF }\end{array}$ & 9 & $(3 \%)$ \\
\hline Professionals & 153 & $31 \%$ \\
\hline Physiotherapist & 93 & $61 \%$ \\
\hline Dietitian & 22 & $14 \%$ \\
\hline $\begin{array}{l}\text { Respiratory } \\
\text { Paediatrician }\end{array}$ & 11 & $7 \%$ \\
\hline Nurse & 9 & $6 \%$ \\
\hline Researcher & 5 & $3 \%$ \\
\hline Respiratory Physician & 5 & $3 \%$ \\
\hline Pharmacist & 2 & $1 \%$ \\
\hline Exercise therapist & 2 & $1 \%$ \\
\hline Junior Doctor & 1 & $1 \%$ \\
\hline Psychologist & 1 & $1 \%$ \\
\hline Physiologist & 1 & $1 \%$ \\
\hline $\begin{array}{l}\text { Healthcare professional } \\
\text { occupation unknown }\end{array}$ & 1 & $1 \%$ \\
\hline \multicolumn{3}{|l|}{ Geographical location } \\
\hline UK & 220 & $45 \%$ \\
\hline North America & 134 & $27 \%$ \\
\hline Europe (non UK) & 19 & $4 \%$ \\
\hline Australia and New Zealand & 7 & $1 \%$ \\
\hline South America & 1 & - \\
\hline Asia & 1 & - \\
\hline Africa & 1 & - \\
\hline Participant location unknown & 105 & $22 \%$ \\
\hline
\end{tabular}




\begin{tabular}{|l|l|}
\hline \multicolumn{2}{|l|}{ Age of survey participants } \\
\hline $\begin{array}{l}\text { Median age (all participants), years } \\
\text { (range) }\end{array}$ & 37 (14-74) \\
\hline $\begin{array}{l}\text { Median age of respondents with CF or } \\
\text { those answering on their behalf, years } \\
\text { (range) }\end{array}$ & 15.5 (1-74) \\
\hline $\begin{array}{l}\text { Median age of respondents with CF } \\
\text { (range) }\end{array}$ & 33 (14-74) \\
\hline $\begin{array}{l}\text { Median age of people with CF whose } \\
\text { parents or family answered on their } \\
\text { behalf, years (range) }\end{array}$ & $8(1-33)$ \\
\hline
\end{tabular}

\section{Appendix Table 2. Top 20 most popular exercise activities for people with CF}

\begin{tabular}{|l|l|l|l|}
\hline Activity & $\begin{array}{l}\text { number of } \\
\text { respondents }\end{array}$ & $\begin{array}{l}\% \text { of total } \\
\text { respondents }\end{array}$ & Mets \\
\hline Walking & 91 & $34 \%$ & 3.5 \\
\hline Run & 86 & $32 \%$ & 8 \\
\hline Swim & 59 & $22 \%$ & 8 \\
\hline Bike & 53 & $20 \%$ & 8 \\
\hline Team sports & 48 & $18 \%$ & 8 \\
\hline Strength training & 46 & $17 \%$ & 8 \\
\hline Gym & 40 & $15 \%$ & 5.5 \\
\hline Trampolining & 33 & $12 \%$ & 4.5 \\
\hline Dance & 31 & $12 \%$ & 6.5 \\
\hline Yoga & 26 & $10 \%$ & 2.5 \\
\hline Gymnastics & 19 & $7 \%$ & 4 \\
\hline Martial Art & 10 & $4 \%$ & 10 \\
\hline HIIT & 9 & $3 \%$ & 8 \\
\hline Cross Fit & 8 & $3 \%$ & 8 \\
\hline Exercise Class & 8 & $3 \%$ & 6.5 \\
\hline Pilates & 8 & $3 \%$ & 3.5 \\
\hline Climbing & 5 & $2 \%$ & 11 \\
\hline Horse riding & 4 & $2 \%$ & 4 \\
\hline Rowing & 4 & 7 \\
\hline Skiing & 4 & $7 \%$ & 7 \\
\hline
\end{tabular}




\section{REFERENCES}

1. Flume PA, Robinson KA, O'Sullivan BP, Finder JD, Vender RL, Willey-Courand DB, et al. Cystic fibrosis pulmonary guidelines: airway clearance therapies. Respiratory care. 2009;54(4):522-37.

2. Dwyer TJ, Alison JA, McKeough ZJ, Daviskas E, Bye PTP. Effects of exercise on respiratory flow and sputum properties in patients with cystic fibrosis. Chest. 2011;139(4):870-7.

3. Dwyer TJ, Zainuldin R, Daviskas E, Bye PTP, Alison JA. Effects of treadmill exercise versus Flutter ${ }^{\circledast}$ on respiratory flow and sputum properties in adults with cystic fibrosis: a randomised, controlled, cross-over trial. BMC Pulm Med. 2017;17(1):14-.

4. Rowbotham NJ, Smith S, Leighton PA, Rayner OC, Gathercole K, Elliott ZC, et al. The top 10 research priorities in cystic fibrosis developed by a partnership between people with CF and healthcare providers. Thorax. 2018;73(4):388-90.

5. Hollin IL, Donaldson SH, Roman C, Aliaj E, Riva D, Boyle M, et al. Beyond the expected: Identifying broad research priorities of researchers and the cystic fibrosis community. J Cyst Fibros. 2018.

6. Ainsworth BE, Haskell WL, Whitt MC, Irwin ML, Swartz AM, Strath SJ, et al. Compendium of physical activities: an update of activity codes and MET intensities. Medicine and science in sports and exercise. 2000;32(9 Suppl):S498-504.

7. Scholes S, Neave A. Health Survey for England 2016: Physical Activity in Adults. In: NHS, editor. https://files.digital.nhs.uk/publication/m/3/hse16-adult-phy-act.pdf2016.

8. Arias-Llorente RP, García CB, Martín JJD. The importance of adherence and compliance with treatment in cystic fibrosis. Cystic fibrosis-Renewed hopes through research. 2012:455-72.

9. Goodfellow NA, Hawwa AF, Reid AJ, Horne R, Shields MD, McElnay JC. Adherence to treatment in children and adolescents with cystic fibrosis: a cross-sectional, multi-method study investigating the influence of beliefs about treatment and parental depressive symptoms. BMC Pulm Med. 2015;15:43-.

10. Radtke T, Nevitt SJ, Hebestreit H, Kriemler S. Physical exercise training for cystic fibrosis. Cochrane Database of Systematic Reviews. 2017(11).

11. Kalaitzis IS, Rowbotham NJ, Smith SJ, Smyth AR. Do current clinical trials in cystic fibrosis match the priorities of patients and clinicans? A systematic review. J Cyst Fibros. 2019.

12. ACTRN12615001361594 Exercise alone versus exercise and positive expiratory pressure as a form of airway secretion clearance in adults with mild cystic fibrosis-related respiratory disease - a feasibility study

https://www.anzctr.org.au/Trial/Registration/TrialReview.aspx?id=369700 [Internet]. First posted 15th December 2015.

13. ACTRN12609000168257 Effects of treadmill exercise versus Flutter ${ }^{\circledR}$ on respiratory flow and sputum properties in adults withcystic fibrosis: a randomised, controlled, crossover trial https://www.anzctr.org.au/Trial/Registration/TrialReview.aspx?id=83651 [Internet]. First posted 6th April 2009. 